\title{
COMMENT
}

\section{Viruses, vaccinations and RSV: Exploring terminology in paediatric virology}

\author{
IOANNIS N. MAMMAS ${ }^{1-4}$, SIMON B. DRYSDALE ${ }^{5,6}$, MARIA THEODORIDOU ${ }^{1,4}$, \\ ANNE GREENOUGH ${ }^{7,8}$ and DEMETRIOS A. SPANDIDOS ${ }^{1,3}$ \\ ${ }^{1}$ Institute of Paediatric Virology; ${ }^{2}$ Paediatric Clinic, Aliveri, 34500 Island of Euboea; \\ ${ }^{3}$ Laboratory of Clinical Virology, Medical School, University of Crete, 71003 Heraklion; \\ ${ }^{4}$ First Department of Paediatrics, University of Athens School of Medicine, 11527 Athens, Greece; \\ ${ }^{5}$ St George's, University of London, London SW17 0RE; ${ }^{6}$ Department of Paediatric Infectious Diseases, \\ St. George's University Hospitals NHS Foundation Trust, London SW17 0QT; ${ }^{7}$ Department of Women and \\ Children's Health, School of Life Course Sciences and Medicine, King's College London, London SE5 9RS; \\ ${ }^{8}$ Asthma UK Centre in Allergic Mechanisms of Asthma, King's College London, London SE1 9RT, UK
}

Received July 31, 2020; Accepted October 24, 2020

DOI: $10.3892 /$ etm.2020.9430

'the examination of the names is the beginning of science'

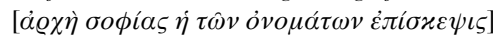

Antisthenes

Accurate and consistent medical terminology is an essential tool in medical education (1). It enables medical students to understand the meaning of each term, medical physicians to communicate with each other and our science to adopt a logical language of high-level understanding and scientific regularity (2). The linking together of the laboratory, research and clinical practice by medical terminology permits medical physicians to understand and follow the scientific developments in their clinical practice (3). However, in medicine, including paediatric virology, there are several etymologically illogical terms, which cause confusion and misunderstanding (4). The majority of these cases are due to historical bias, which can be explained or justified by historians of medicine, but are interpreted with difficulty by medical students and junior medical staff. The adoption of these terms leads to the continuation of the historical bias, confusion among clinicians and potential misunderstanding.

The term virus is an example. It derives from the Latin word virus meaning toxin or poison (5). It was in 1892, almost 128 years ago, when the biologist, Dimitri Ivanokvski in

Correspondence to: Professor Demetrios A. Spandidos, Laboratory of Clinical Virology, Medical School, University of Crete, 71003 Heraklion, Greece

E-mail: spandidos@spandidos.gr

Key words: viruses, vaccinations, RSV, terminology, paediatric virology
St. Petersburg, Russia, demonstrated that infectious extracts of tobacco plants with tobacco mosaic disease remained infectious following filtration, suggesting that tobacco mosaic disease might be caused by a toxin produced by bacteria (6). Six years later, in 1898, the Dutch scientist, Martinus Beijerinck, reported similar experiments with bacteria-free filtered extracts and introduced the term virus for the filterable and submicroscopic sized causative agent of the tobacco mosaic disease (7). Although he described this agent as a contagium vivum fluidum, his term was based on the hypothesis by Ivanovski that this agent was not a microorganism itself, but a toxin. The Greek term for virus, ios, derives from the ancient Greek verb iimi, meaning 'to move, to cause movement, to put something into something else, to throw the arrow, the poison, the toxin'. Although the choice of this term was based on the poison's translation into ancient Greek, some of the actions of this ancient Greek verb describe, in a unique manner, some of the characteristics of viruses. In the Greek term Iology, ios has been connected with logos, coming from the Greek verb lego, meaning 'to talk about'. Both terms, Virology and Iology, describe the study of viruses.

The term vaccination is another example. The word vaccination derives from the Latin word vacca meaning 'the cow' (5). This term was created in order to describe the method of inoculation of pustular material obtained from lesions in cows affected by cowpox, which was developed in 1796 by Dr Edward Jenner, an English country doctor, who later became known as the 'Father of Immunology' (8). The method, which was based on his clinical observation that cowpox infection protected humans against smallpox, replaced variolation, which had been used in clinical prac- 
tice for smallpox prevention before Dr Jenner's observation. The word variola, commonly used for smallpox, derives from the Latin word varius, meaning 'spotted with marks on the skin' indicating the appearance of the characteristic skin lesions of smallpox (9). The term small pockes was first used in England at the end of the 15th century to distinguish the skin lesions presented in smallpox from syphilis, which was then known as the great pockes (10). Both vaccination and variolation were types of inoculation. The word inoculation derives from the Latin word inoculare, meaning 'to graft', to introduce an effective agent into an organism. The first reference to variolation in Western medicine was in 1714 in the medical journal Philosophical Transactions, when the Royal Society of London received a letter from the Greek doctor Emmanuel Timonis, who originated from the island of Chios, describing his clinical practice in Constantinople (11). A similar letter was published in the same volume of Philosophical Transactions by the Greek Jacobus Pylarinus, who originated from the island of Cephalonia and was also practicing medicine in Constantinople. He mentioned that he had used his method in children since the great epidemic of smallpox in Constantinople in 1701 (11). While the use of the term variolation was limited to describe the historical method of smallpox's prevention via inoculation, the term vaccination was later adopted to mean immunization against any disease. Despite the valuable contribution of Dr Edward Jenner and his predecessors, the term vaccination is another paradigm of false terminology in contrast to the term immunization. Immunization was adopted in the following years to describe the process of the development of adequate immunity against infectious diseases. The terms vaccination and immunization are often used interchangeably; hopefully the latter term is more inclusive and etymologically correct.

Is respiratory syncytial virus (RSV) an accurate medical term? Identified in 1956 from the respiratory secretions of chimpanzees with bronchiolitis, RSV was first known as the chimpanzee coryza agent $(12,13)$. Interestingly, the second word of this term, coryza, is a Hippocratic ancient Greek word related to influenza-like and upper respiratory tract illness, rather that lower respiratory tract infection (14). The virus was renamed as RSV due to its characteristics of infecting children's' airways and generating gigantic syncytial cells in tissue culture. Although formation of syncytia has been considered as the hallmark of the cytopathic effect caused by RSV, syncytia also occur when host cells are infected with several other viruses, including herpes simplex virus 1 (HSV-1), human immunodeficiency virus (HIV), coronavirus (CoV), human T-lymphotropic virus (HTLV) and metapneumovirus (15-19). This means that the formation of syncytia, derived from the Greek word syn meaning 'together' and kytos meaning 'the cyst, the box, the cell', is not pathognomonic of this virus. Moreover, RSV detection is now based on modern molecular virology techniques, such as reverse transcription-polymerase chain reaction (RT-PCR) and the rapid antigen detection tests (RADTs), and not tissue culture, which is now rarely used in clinical practice.

Everybody agrees it is time to remove historical biases in medical terminology and to adopt accurate medical terms. However, the level of difficulty of this is uncertain. Recently, the International Committee on Taxonomy of Viruses (ICTV), which authorizes and organizes the classification and naming of virus species, taxonomically reclassified RSV into the orthopneumovirus genus (20); the name of the virus, RSV, remains the same. Until 2016, the ICTV classified pneumoviruses, such as RSV and HMPV in the paramyxoviridae family. However, it was realized quite some time ago that the pneumoviruses are only distantly related to paramyxoviruses and in fact are more closely related to Filoviruses, such as Ebola virus (e.g., for the RDRP or L gene). Therefore, in 2016, the pneumoviruses were re-classified as a separate family, the pneumoviridae. As part of the ongoing effort to make virus classification more systematic, and already having a genus termed metapneumovirus, the ICTV renamed the genus with the earliest known pneumoviruses as the orthopneumovirus genus (21). This change offers a better systematic approach to virus taxonomy. However, it is uncertain how accurate and informative this term can be in clinical practice.

Ortho- in Greek means 'right, correct, straight', and this prefix is the same in the terms orthopaedics and orthodontics. In organic chemistry, this prefix is used to indicate the specific position of non-hydrogen substituents on hydrocarbons and is used to discriminate other positions termed as meta- meaning 'after' and para- meaning 'close to'. In virology, the prefixes ortho-, meta- and para- are used to discriminate sequencing differences in the genetic analysis of various taxonomic groups. However, the choice of each prefix is not related to specific viral structures or chemical properties. The differences between the orthopneumovirus and metapneumovirus are based on the different gene arrangements in their genomes. The prefix ortho- is used to taxonomise several viruses' families and genera, such as the orthomyxoviridae family, which includes influenza $A$ and $B$ viruses. The use of orthoindicates the description of the main representative of each group. In the past RSV was classified in the paramyxoviridae family. Could this prefix really solve, preserve or aggravate existing confusion?

The term pneumo- refers to the lungs; however, its etymology is related to the air and not the lungs. Pneuma means 'the blow of the wind', 'the breath', 'the soul-heart' in ancient Greek, 'the air'. It comes from the ancient Greek verb pneo meaning 'to blow, to breath'; pnoe is 'breathing'. For the lungs, the ancient Greek word used by Hippocrates during the 4th century BC was pneumon (14). This word also comes from the ancient Greek verb pneo and remains the same in modern Greek. Pneumovirus means a virus related to the air; not the lungs. Similarly, pneumoviridae is the family of viruses related to the air. Adding $\mathrm{n}$ in both terms, pneumonovirus and pneumonoviridae family would be related to the lungs. Bronchiolovirus would be a virus related to the bronchioli, which represent the anatomical site of inflammation in RSV-associated bronchiolitis.

In the modern era of precision medicine, accurate and consistent terms, which describe precisely their meaning, are easily learnt and necessary (22). Their etymology can be highly informative. Despite the difficulty of this task, the need to reform the medical terminology is urgent. These efforts will reduce misunderstanding and confusion in medical education and will guarantee high-level consistency of our science. Prioritizing modern medical terminology and harmonizing 
it with recent achievements in research will promote medical education and facilitate clinical practice by future generations of medical physicians. Paediatric virology is a pioneering scientific field and its medical terminology should be based on new advances of genetic sequencing, molecular virology and precision medicine.

\section{Acknowledgements}

This article is published in the context of the foundation of the Institute of Paediatric Virology (IPV; https:// paediatricvirology.org) based on the island of Euboea (Greece), under the auspices of the World Academy of Sciences (WAS) and the support of the Department of Clinical Virology of the University of Crete School of Medicine and the First Department of Paediatrics of the University of Athens School of Medicine. We would like to thank all the members of the IPV for their valuable comments and corrections.

\section{Funding}

No funding was received.

\section{Availability of data and materials}

Not applicable.

\section{Authors' contributions}

All authors (INM, SBD, MT, AG and DAS) contributed to the conception and design of this manuscript, wrote the original draft, edited and critically revised the manuscript, read and approved the final manuscript.

\section{Ethics approval and consent to participate}

Not applicable.

\section{Patient consent for publication}

Not applicable.

\section{Competing interests}

INM, DAS and MT are co-founders of the Institute of Paediatric Virology (IPV). SBD is Member of the Advisory Academic Board (AAB) of the IPV. AG in Chair of the Advisory Academic Board (AAB) of the IPV. DAS is the Editor-in-Chief for the journal, but had no personal involvement in the reviewing process, or any influence in terms of adjudicating on the final decision, for this article.

\section{References}

1. Brahler CJ and Walker D: Learning scientific and medical terminology with a mnemonic strategy using an illogical association technique. Adv Physiol Educ 32: 219-224, 2008.
2. Chivers RC: Letter: Medical terminology. BMJ 4: 346-347, 1975.

3. Gordon BL: Standard medical terminology. JAMA 191: 311-313, 1965.

4. Mammas IN, Theodoridou M, Kramvis A, Thiagarajan P, Gardner S, Papaioannou G, Melidou A, Koutsaki M, Kostagianni G, Achtsidis V, et al: Paediatric Virology: A rapidly increasing educational challenge. Exp Ther Med 13: 364-377, 2017.

5. Spandidos DA: Virology. Litsas Editions, 1995 (In Greek).

6. Ivanovsky D: Concerning the mosaic disease of the tobacco plant. St Petsb Acad Imp Sci Bul 35: 67-70, 1882.

7. Sankaran N: On the historical significance of Beijerinck and his contagium vivum fluidum for modern virology. Hist Philos Life Sci 40: 41, 2018

8. Willis NJ: Edward Jenner and the eradication of smallpox. Scott Med J 42: 118-121, 1997.

9. Lustig A and Levine AJ: One hundred years of virology. J Virol 66: 4629-4631, 1992.

10. Moore JC: The History of the Smallpox. Longman, London, 1815.

11. Poulakou-Rebelakou E and Lascaratos J: Emmanuel Timonis, Jacobus Pylarinus and inoculation. J Med Biogr 11: 181-182, 2003.

12. Chanock R, Roizman B and Myers R: Recovery from infants with respiratory illness of a virus related to chimpanzee coryza agent (CCA). I. Isolation, properties and characterization. Am J Hyg 66: 281-290, 1957.

13. Chanock R and Finberg L: Recovery from infants with respiratory illness of a virus related to chimpanzee coryza agent (CCA). II. Epidemiologic aspects of infection in infants and young children. Am J Hyg 66: 291-300, 1957.

14. Mammas IN and Spandidos DA: Paediatric Virology in the Hippocratic Corpus. Exp Ther Med 12: 541-549, 2016.

15. Resnick L and Novatt G: Human T-cell lymphotropic viruses: Syncytia formation. JAMA 255: 3421, 1986.

16. Symeonides M, Murooka TT, Bellfy LN, Roy NH, Mempel TR and Thali M: HIV-1-induced small T cell syncytia can transfer virus particles to target cells through transient contacts. Viruses 7: 6590-6603, 2015.

17. Dubois J, Cavanagh MH, Terrier O, Hamelin MÈ, Lina B, Shi R, Rosa-Calatrava M and Boivin G: Mutations in the fusion protein heptad repeat domains of human metapneumovirus impact on the formation of syncytia. J Gen Virol 98: 1174-1180, 2017.

18. Qian Z, Dominguez SR and Holmes KV: Role of the spike glycoprotein of human Middle East respiratory syndrome coronavirus (MERS-CoV) in virus entry and syncytia formation. PLoS One 8: e76469, 2013

19. Carmichael JC, Starkey J, Zhang D, Sarfo A, Chadha P, Wills JW and Han J: Glycoprotein D of HSV-1 is dependent on tegument protein UL16 for packaging and contains a motif that is differentially required for syncytia formation. Virology 527: 64-76, 2019.

20. International Committee on Taxonomy of Viruses (ICTV): ICTV Taxonomy history: Human orthopneumovirus. ICTV, 2019. https://talk.ictvonline.org/taxonomy/.

21. Rima B, Collins P, Easton A, Fouchier R, Kurath G, Lamb R, Lee B, Maisner A, Rota P and Wang L; ICTV Report Consortium: ICTV Virus Taxonomy Profile: Pneumoviridae. J Gen Virol 98: 2912-2913, 2017.

22. Mammas IN, Drysdale SB, Rath B, Theodoridou M, Papaioannou G, Papatheodoropoulou A, Koutsounaki E, Koutsaftiki C, Kozanidou E, Achtsidis V, et al: Update on current views and advances on RSV infection (Review). Int J Mol Med 46: 509-520, 2020

This work is licensed under a Creative Commons Attribution-NonCommercial-NoDerivatives 4.0 International (CC BY-NC-ND 4.0) License. 